\title{
En busca de una genealogía de las misiones universitarias reformistas
}

\section{(4) Marcela Mollis}

\begin{abstract}
Resumen
Nos interesa indagar la relación entre la retórica que encarna la universidad como máxima institución del sistema educativo argentino y la formación para el trabajo en fábrica o industria junto con el lugar asignado a los estudiantes trabajadores en sentido amplio. Hemos recuperado pocos análisis históricos que discuten la funcionalidad del ideario y el modelo institucional reformista a la luz de los requerimientos del mundo del trabajo. En este sentido, esperamos dar cuenta de la relación entre las voces reformistas que representaron epocalmente el modelo universitario dominante versus el nuevo paradigma universitario destinado a trabajadores y trabajadoras: la Universidad Obrera Nacional (UON) oficialmente reconocida como Universidad Tecnológica Nacional (UTN) a partir de 1959.
\end{abstract}

\section{Looking for a genealogy of reformist university missions}

\begin{abstract}
We want to research the relationship between the rhetoric embodied by the university as the highest institution of the Argentine educational system and training for work in the factory or industry along with the place assigned to working students in the broad sense. Few historical studies analyze the functionality of the reformist institutional model in the light of the requirements of factories \& enterprises. We hope to account for the relationship between the reformist voices that historically represented the dominant university model versus the new university paradigm aimed at workers: National Workers University (UON) officially recognized as National Technological University (UTN) starting of 1959.
\end{abstract}

\section{Palabras clave:}

Universidad reformista, estudiantes trabajadores, misiones universitarias, profesionalización.

\section{Keywords:}

reformist, workers, university missions, professional college students. 


\section{Modelos universitarios en diálogo}

Existe consenso entre algunos historiadores de la universidad latinoamericana y argentina, en torno a la misión dominante de la universidad reformista reconocida como profesionalizante, es decir, orientada a la formación general o integral de abogados, médicos, ingenieros, arquitectos, entre otros, para el ejercicio de las profesiones liberales (Cano, 1985; Frederic, Graciano y Soprano, 2010; Halperín Donghi, 1962; Mollis, 2015; Perez Lindo, 1986; Steger, 1974. En esta dirección, nos interesa indagar la relación entre la retórica que encarna la universidad como máxima institución del sistema educativo argentino y la formación para el trabajo en fábrica o industria junto con el lugar asignado a los estudiantes trabajadores en sentido amplio. Hemos recuperado pocos análisis históricos que discuten la funcionalidad del ideario y el modelo institucional reformista a la luz de los requerimientos del mundo del trabajo (Casali, 2005; Pronko, 1997; Puiggrós, 1994 y 2003). En este sentido, esperamos dar cuenta de la relación entre las voces reformistas que representaron epocalmente el modelo universitario dominante versus el nuevo paradigma universitario destinado a trabajadores y trabajadoras: la Universidad Obrera Nacional (UON) oficialmente reconocida como Universidad Tecnológica Nacional (UTN) a partir de 1959. Los tempranos estudios de Marcela Pronko (1997), Inés Dussel (1990), Inés Dussel y Pablo Pineau (1994), Pablo Pineau (1997) y el análisis más reciente sobre el concepto de "trabajo" de Carlos Casali (2005) toman en cuenta los debates parlamentarios en torno a las Leyes 13031 y 13229. Los autores describen testimonios de un grupo de diputados del oficialismo y de la bancada radical; citan a Gabriel del Mazo, Luis Dellepiane, Antonio Sobral, Ricardo Guardo, entre otros, cuyo criticismo hace hincapié en las deficiencias de la técnica y el concepto del trabajo utilitario/productivo, por un lado, y por el otro, la falta de cultura general y el exceso de especialización caracterizados como saberes impropios de la máxima casa de altos estudios (Casali, 2005; Pronko, 1997).

1. En el capítulo titulado "Origins of the Idea of a University" (2003, p.7-24), Rothblatt explica fundamentalmente el legado de John Henry Cardinal Newman a partir de 1850 , quién supo conjugar una concepción moderna de universidad religiosa superadora de la influyente idea medieval de instituciones corporativas portadoras de donantes y privilegios, junto con la idea de enseñanza universal. Ante la pregunta por el significado de la universidad, Newman responde: "Una universidad se define por su misión de enseñanza universal, más que por cualquier otra misión".

Para enriquecer las interpretaciones sobre esta temática desde el punto de vista teóricohistórico, recuperamos los aportes del historiador Sheldon Rothblatt (2006 y 2003) ${ }^{1}$ quien compara las "ideas" de aquellos fundadores que configuraron tres tradiciones universitarias a través de las particulares misiones de la Universidad de Oxford, de Londres y de Berlín. Dichas ideas fundantes nutren de modo diferenciado, distintos modelos universitarios en la geografía europea que, a nuestro juicio, han tenido impacto en el modelo reformista argentino.

Rothblatt (2006) reconstruye las ideas que animaron al Cardenal John Henry Newman converso del anglicanismo al catolicismo- a crear en el siglo XIX un tipo de universidad anglosajona moderna (inspirado a su vez en Oxford y Cambridge, dando lugar al modelo "Oxfbridge"). Este espacio educativo debía ser integral, formador del carácter y la moral de los jóvenes con cultura general y religiosa en un ámbito de convivencia orientada al desarrollo de la camaradería y amistad (el campus) (Rothbaltt, 2006, p.34-36). Las artes liberales adquieren protagonismo como saberes propedéuticos (sobre todo las disciplinas literarias, filosóficas e históricas), en tanto la verdadera misión de estas universidades y sus facultades (colleges) es "la enseñanza universal" sin fines prácticos o pragmáticos. Por otra parte, Newman muestra su disconformidad hacia la universidad de Londres de 1838 ubicada en el centro de la ciudad, que se destaca por la formación profesional que ofrece (Medicina fundamentalmente), en un ambiente urbano opuesto al campus, cuya dinámica impacta negativamente en las formas de estudio y el vínculo entre sus estudiantes. Por último, valora y destaca el modelo de la Universidad de Berlín, cuyo fundador Wilhelm Von Humboldt diseñó un formato profesoral en el que conjugaba la idea de libertad de aprender, libertad de cátedra o de enseñar con la libertad de investigar, recreando la figura del profesor-investigador que formaba discípulos en sus cátedras o institutos de investigación (Mollis, 1994). 
El breve relato sobre misiones derivadas de "ideas fundantes" de las figuras portadoras de dichas tradiciones universitarias, resulta ilustrativo para develar algunas dimensiones del trasfondo del paradigma reformista: ${ }^{2}$ tres misiones universitarias -enseñanza, investigación y extensión- parecen recuperar a modo de capas geológicas diversas tradiciones universitarias europeas del siglo XIX, quedando por fuera la formación para el trabajo productivo, más allá de la preparación para el desempeño de las llamadas profesiones liberales y la socialización política de líderes y dirigentes nacionales.

Las palabras de Deodoro Roca en el Drama Social de la Universidad orientan este apartado en la dirección señalada: las universidades europeas brindaron a los referentes más significativos del reformismo su fuente de inspiración para construir una retórica moderna a la hora de poner en marcha la Reforma Universitaria y su impronta institucional:

Fue la Universidad acaso, lo más alto que Europa dio durante el siglo XIX. Por ello más que todo, fue respetada en el mundo. Universidad representaba allí universalización en una totalidad de la técnica, la investigación, de la enseñanza, del espíritu. Los grandes hombres, con su ejemplaridad y teorías habían dado a las universidades la más alta atmósfera y la profunda tonalidad espiritual. Una burguesía rica, optimista, educada en la tradición [...] sostenía todo el sistema [...] Y como cima de todo-flor y también fruto-. Se movía el ideal humanitario que Humboldt bien definiera: el ideal de la personalidad, realizándose en el plano de una educación estético-humanista [...] Aparte del espectáculo grotesco que ofrece la Universidad merced a su penuria y falsificación, hoy se sabe que no habrá verdaderamente Reforma, mientras no se reforme profundamente la estructura del Estado; y esto es lo más importante: en el 18 era un "sentimiento" acaso un atisbo. En el 36 es un estado clarísimo de conciencia y una voluntad inequívoca. Lo social sí pero el hombre también [...] El problema político se torna inseparable del problema de la cultura. He aquí una zona desatendida en el paisaje de la Reforma. No verla con anticipada claridad sería, a esta altura, un mal síntoma. (Roca citado por Kohan, 1999, p.126-127)

El autor del Manifiesto Liminar denuncia las limitaciones que enfrentaba el movimiento reformista en la década del treinta con llamativa anticipación. Política y cultura, ambas dimensiones indispensables para conquistar la reforma del Estado en la direccionalidad aspirada por "el Hereje Deodoro Roca" (Kohan, 1999). Así según Roca, la política y la cultura o la cultura y la política, se habían convertido en dos asignaturas pendientes del movimiento reformista para lograr la transformación anhelada más allá de la propia retórica del movimiento reformista.

Las referencias que hemos descripto en este apartado, constituyen al menos, un punto de partida para comprender una cierta genealogía de las tres misiones que encarnan el modelo de la universidad reformista: docencia, investigación y extensión. Estas misiones, junto al gobierno tripartito representativo de los claustros de profesores, graduados y estudiantes, le dieron al reformismo una configuración propia y única con respecto a los modelos existentes en las metrópolis europeas y norteamericanas. La única relación posible entre universidad y formación para el trabajo productivo (en fábrica o industria) más allá de la formación profesional a la que hemos aludido, fue concebida bajo la modalidad extensionista, es decir, a través de la función extensión universitaria que estrechaba lazos entre los universitarios y otros actores sociales en sentido amplio, o trabajadores/trabajadoras de manera específica.

En el apartado siguiente, brindaremos algunos testimonios reveladores sobre el modo de pensar de algunos universitarios /intelectuales de izquierda respecto de ese particular vínculo entre "universidad y estudiantes obreros/trabajadores".
2. Véase especialmente la obra de los reformistas Gabriel del Mazo (1941) y Alfredo Palacios (1957); también, Ciria y Sanguinetti (1985), Portantiero (1978). 


\section{Universitarios-intelectuales-reformistas y obreros-trabajadores: una disputa política y cultural}

A la luz de la actuación e intervención política de los intelectuales universitarios en el socialismo y en el anarquismo a partir de los años treinta, la historiografía en general ha interpretado la emergencia de las experiencias político-culturales reformistas como parte de un proceso más amplio de democratización del sistema político, sobre todo desde la emergencia e instauración de un régimen de gobierno representativo como el de Yrigoyen. Como consecuencia de ese fenómeno, se fue acelerando una diferenciación entre la esfera política y la cultural que permitió redefinir los roles vigentes hasta ese momento, de los políticos y de los intelectuales. Hemos observado en el discurso reformista de diversas agrupaciones, una repetida alusión a la ausencia de democracia en la cultura política peronista y la denuncia de prácticas autoritarias fascistoideas. En este sentido, creemos oportuno recuperar tres trabajos referenciales que contribuyen a esclarecer nuestro problema. Nos referimos a las obras de Osvaldo Graciano (2008), Pablo Buchbinder (2005) y Federico Neibürg (1998).

El aporte de Graciano resulta consistente con los argumentos presentados más arriba con respecto al reconocimiento del predominio de la profesionalización liberal de los universitarios durante la década del treinta, que actúa como catalizador del contexto neoconservador. El autor muestra de qué manera el cambio de estrategia en la política universitaria neoconservadora de ese momento promovió la ampliación de propuestas universitarias desde el Partido Socialista, fundadas en el latinoamericanismo, el antiimperialismo, el liberalismo democrático y el humanismo. A través de su análisis, es posible comprender de qué manera estos intelectuales reformistas y socialistas idearon una política académica y científica que intentaba posicionar a la universidad como actor clave para la reflexión y resolución de los problemas sociales y económicos del país de ese momento. La intervención de los intelectuales socialistas y anarquistas en el campo político a partir de 1943, llevó como bandera la crítica en clave culturalista de la crisis de la civilización contemporánea y de las prácticas fascistas, entre las que ubicaban al fenómeno del peronismo.

El propio Graciano, va más allá de esta interpretación, al inscribir estas transformaciones en procesos de conformación de campos disciplinares específicos que contribuyeron a dotar de autonomía y legitimidad a las modalidades de intervención particulares de los actores universitarios. Es así como muchos universitarios desplegaron su proyección política en la esfera pública y se fue configurando en forma simultánea la democratización y la profesionalización de la política. Entre tanto, el desarrollo burocrático estatal, el control de la enseñanza superior y la conformación de campos de producción y actuación cultural iban ganando una identidad mesocrática, referenciada en las clases medias: "En ese marco, la clausura de las dos condiciones centrales para el activismo del intelectual autónomo del partido -pervivencia del orden democrático y control de la universidad por parte de los reformistas- los obligó a inscribir sus luchas en el terreno político partidario" (Graciano, 2008, p.18).

Ahora bien, Graciano analiza exclusivamente la afiliación al Partido Socialista y no a otra organización política, ya que el socialismo les permitía actualizar las prácticas de una cultura política conocida, asentada en la "palabra y lo escrito", a partir de una sólida y estructurada organización partidaria y una firme escuela político-doctrinaria. El autor recorre la participación de estos universitarios en la política nacional, caracteriza su actuación en espacios directivos del Partido, en aparatos culturales o en el parlamento, y señala matices en las posiciones que mantuvieron acerca de la concepción de socialismo y su relación con el materialismo histórico. Relaciona, además, estos particulares acercamientos con las circunstancias que redefinieron sus estrategias de participación en la esfera política y en el campo cultural. Las coyunturas políticas de 
la década, marcadas por fenómenos políticos interpretados de modo conservador, por sus expresiones dictatoriales o simbología fascista promovieron un "corrimiento" hacia posturas de defensa de la democracia, de las libertades individuales y políticas y de denuncia de una crisis de la civilización occidental contemporánea. Este autor logra mostrar que los estudiantes universitarios de izquierda, en particular los socialistas, se van incorporando a la esfera pública interviniendo en los debates y disputas de interés nacional, con un explícito compromiso primero independiente y a posteriori atravesado por la pertenencia a un partido político. ${ }^{3} \mathrm{El}$ análisis de las estrategias y modalidades de participación en experiencias culturales y prácticas intelectuales, tanto de los universitarios socialistas como de quienes se integraron al anarquismo, facilita la comprensión del entramado político-cultural que compartía su vinculación con los sectores obreros. La reconstrucción histórica de los debates y las formas de actuación de algunos de estos grupos-especialmente los referenciados en el movimiento libertario- permite abonar la hipótesis acerca del lugar que ocuparon los universitarios en la construcción de una cultura alternativa para los trabajadores ( $y$, me permito agregar, sin trabajadores).

Por otra parte, desde el punto de vista de la institución universitaria, Buchbinder (2005) afirma que, durante los años veinte y treinta, esta se había convertido para los líderes peronistas en el reducto de los "hijos del privilegio", cuyo reconocimiento animó una "oposición antioligarca" de parte de actores peronistas hacia el recinto universitario.

El peronismo nació tras el golpe de junio de 1943, en un contexto de lucha entre nacionalistas y liberales. Por primera vez quedó definido el par antinómico peronista/ antiperonista, como referente de identidades en construcción y de una singular disputa histórica. Solo después de ganar las elecciones de 1946 se promovió la fusión en un nuevo partido y se fueron añadiendo nuevos contenidos. A una identidad "debatida" en la movilización callejera se sumó una referencia partidaria y, poco tiempo después, una política de Estado que encarnaba la doctrina peronista. En 1955 otro golpe militar, apoyado por los civiles de la llamada Revolución Libertadora (Iglesia Católica, comunistas, conservadores, asociaciones estudiantiles y grupos de intelectuales), le puso fin al segundo gobierno de Perón. La singular disputa entre peronistas y antiperonistas adquirió significados de violencia y proscripción.

En una dirección coincidente con los análisis precedentes referidos a la invención de un peronismo que emerge como significante 4 ante la oposición beligerante del movimiento estudiantil reformista y otros intelectuales de partidos opositores, Neibürg (1998) se ocupa del entramado de interpretaciones que le fueron dando cuerpo a dicha invención. En su libro, Neibürg reflexiona sobre la relación constitutiva entre representación y realidad, y más específicamente sobre la relación constitutiva entre la génesis social de los intérpretes de la realidad, de sus interpretaciones y de sus objetos. El autor tiene la aspiración de comprender la lógica social subyacente a la existencia de esos debates que han tenido como objeto al peronismo, la génesis de las figuras intelectuales que en ellos participaron y sus efectos en la construcción del propio peronismo como fenómeno social y cultural:

... tal vez pocas palabras tienen, como la palabra peronismo, semejante capacidad para invocar, al mismo tiempo, violentos desacuerdos -adhesiones y repudios fundados en las más variadas interpretaciones-y una rara unanimidad: liderazgo revolucionario, experiencia nacional-popular, dictadura bonapartista, populismo autoritario, efecto de la acción de un genio maligno fueron solamente algunas de las expresiones utilizadas por políticos e intelectuales para describir lo que todos ellos coincidieron en calificar como una propuesta, positiva o negativa, de constitución de la nación, una forma perversa o progresista de integración del pueblo de la sociedad argentina. Los intelectuales no solo no han estado al margen de esta representación, sino que han participado activamente en su fabricación. (Neibürg, 1998, p.15)
A nuestro juicio, esta interpretación nos acerca a un debate actual y necesario acerca del significado que asume la autonomía universitaria en cada momento histórico para reconocer la vinculación permanente entre la figura del intelectual y la del político, aun desde su intento de diferenciación de roles.

4. Ernesto Laclau (1996) define el concepto de "significante vacío" como un "significante sin significado"; en consecuencia, un significante vacío sólo puede surgir si la significación en cuanto tal está habitada por una imposibilidad estructural y si esta imposibilidad sólo puede significarse a sí misma como interrupción (subversión, distorsión) de la estructura del signo (1996: 69-71). Laclau señala además que "la función de los significantes vacíos es renunciar a su identidad diferencial a los efectos de representar puramente la identidad equivalencial de un espacio comunitario; ellos no pueden construir esta identidad equivalencial como algo perteneciente al orden de las diferencias" (1996, p.78) 
5. La Ley 13031 de 1947 -publicada en 1948- anulaba el principio de autonomía universitaria y prácticamente suprimía la participación estudiantil en el gobierno universitario; los rectores eran designados directamente por el poder ejecutivo y los decanos por el consejo directivo a partir de una terna elevada por el rector. Los consejos directivos estaban compuestos por siete representantes de los profesores titulares y cuatro por los adjuntos. Los estudiantes tenían un representante con voz y sin voto. Además, se creó el Consejo Universitario Nacional, integrado por el ministro de Instrucción y Justicia y los rectores de las universidades.
Resulta interesante descubrir coincidencias entre algunos autores (Buchbinder, 2005; Girbal-Blacha, 2005; Graciano, 2008 Neibürg, 1998; Toer, 1988) en cuanto a que el golpe de Estado de 1943 que derrocó a Castillo llevó al poder a grupos católicos, nacionalistas y conservadores. Así comenzó una profunda transformación de la instrucción pública con una orientación confesional que introdujo la enseñanza obligatoria de la religión en las escuelas. Las universidades fueron intervenidas y muchos estudiantes detenidos. Se decretó la suspensión de las actividades de los centros de estudiantes, la separación de algunos miembros del cuerpo docente y la expulsión de los estudiantes señalados por su militancia opositora. Las continuas protestas de los estudiantes junto con destacadas figuras del ámbito científico promovieron, desde febrero de 1945, un proceso de normalización que permitió la reincorporación de docentes cesanteados, la vuelta al gobierno de la universidad de quienes habían sido desalojados y el inicio de un lento proceso hacia la recuperación de la autonomía. En julio de 1945 una conferencia nacional de rectores de todas las universidades se pronunció enfáticamente a favor del respeto irrestricto de la autonomía universitaria y la vuelta a la normalidad institucional. Para Buchbinder la victoria de Perón en las elecciones de febrero de 1946 supuso una derrota política para el sistema universitario que, prácticamente en su conjunto, había apoyado a la unión democrática. En mayo de 1946, las universidades fueron nuevamente intervenidas. ${ }^{5}$ Los fundamentos del decreto de intervención hacían referencia a la necesidad de controlar la creciente politización del ámbito universitario. Aunque las universidades quedaron sometidas al poder político debido a la falta de autonomía, algunos autores (Arata y Mariño, 2013; Buchbinder, 2005; Puiggrós, 2003) reconocen que no se produjeron cambios visibles en las formas de organización didáctica y pedagógica debido a que no hubo cambios sustantivos en los contenidos de las carreras.

Por otra parte, Buchbinder describe que durante el segundo gobierno de Perón se pusieron en marcha políticas de investigación científica tales como la creación de premios a la investigación, se conformó un Consejo Superior de Investigaciones Científicas y Publicaciones, y a partir de 1947 se instauró estatutariamente el régimen de dedicación exclusiva a la docencia. Hasta principios de 1950 se crearon catorce nuevas facultades en las cinco universidades nacionales: Odontología y Arquitectura en la Universidad de Buenos Aires; Ciencias Económicas y Filosofía y Humanidades en la Universidad de Córdoba; Ciencias Económicas en la Universidad de Tucumán y Ciencias Médicas en la Universidad de Cuyo, y a partir de 1950 se creó la Junta de Investigaciones Científicas y Experimentaciones, que dependía del Ministerio de Defensa. En 1951 se creó la Dirección Nacional de Investigaciones Técnicas y el Consejo Nacional de Investigaciones Técnicas y Científicas, y más tarde la Comisión Nacional de Energía Atómica (CNEA).

Otro estudio revelador del clima de época que pone el foco en los intelectuales durante el peronismo es el de Fiorucci (2011) que reconoce que "las imágenes derivadas de la frase 'alpargatas sí libros no' aparentemente lanzada como grito de guerra por los obreros el 17 de octubre de 1945 [...] han clausurado las indagaciones sistemáticas sobre la vida intelectual y cultural del periodo y ocultan las contradicciones de un régimen que estuvo dominado por impulsos dispares en el área” (contratapa).

Desde el punto de vista de la Federación Universitaria Argentina (FUA) y de la Federación Universitaria de Buenos Aires (FUBA), la consigna a favor de la unidad obrero-estudiantil estuvo presente en cada uno de los Congresos y proclamas del movimiento estudiantil. La estrategia predominante de aproximación a los sectores populares fue la "extensión universitaria"; en el caso puntual de los cursos de extensión para obreros del Centro de Estudiantes de Ingeniería (CEI) de la UBA, su orientación se asemejaba con la modalidad de tipo "asistencialista" más que a la promoción social y vinculación política. Esta situación se agravó durante ambos gobiernos peronistas, 
dada la representación que desde 1943 en adelante, se fue configurando como fuerte prejuicio socialista:

[Los fubistas instalaron] al peronismo dentro de la contradicción democracia-fascismo, producto de la guerra reciente, identificándolo con los regímenes fascistas. El uso, por parte del peronismo, de la propaganda masiva partidaria y gubernamental; el carácter formal de la actividad parlamentaria; el tono marcadamente nacional de su discurso, en un contexto en que, por un lado, en los antecedentes locales sobre el tema, predominaba el nacionalismo de derecha, por otro, se venía de una guerra mundial en la que lo nacional, se identificó con el expansionismo imperialista del Eje. (Mangone y Warley, 1984)

En un estudio de Martínez Mazzola (2011, p.105-125) -atractivo por la recuperación de los discursos políticos de socialistas como Alicia Moreau de Justo- muestra la asociación que algunos intelectuales socialistas construyeron entre peronismo y "totalitarismo":

En septiembre de 1950, Alicia Moreau de Justo advertía: “no es necesario recurrir al ejemplo de Rusia para demostrar el antagonismo irreductible que existe entre el socialismo y los sistemas totalitarios. Nosotros estamos viviendo aquí una situación parecida al caso ruso. No tiene aún aquellas proporciones, pero amenaza adquirirlas con el tiempo". (Martínez Mazzola, 2011, p.105) ${ }^{6}$

De acuerdo a Martínez Mazzola, la dirigente socialista planteaba una asociación directa entre peronismo y estalinismo. Dicho vínculo fue posible por la utilización del concepto "totalitarismo" que le permitió ampliar su referencia limitada a los "nazi-fascismos" para incluir también al régimen soviético. En su trabajo, Martínez Mazzola observa que la historiografía en general, refiere a las interpretaciones socialistas fuertemente influidas por el contexto de lucha contra el "totalitarismo" nazi-fascista y prácticamente no se han asociado los usos del concepto totalitario con el estalinismo. Sin embargo, esta cita aporta un ejemplo interesante al respecto.

Distintos elementos discursivos de parte de las izquierdas contribuyeron a reforzar la concepción "totalitaria" que los universitarios construyeron del peronismo. De alguna manera, estas construcciones discursivas inhabilitaron a los actores de izquierda reformistas para comprender algunos cambios democratizadores que se produjeron en aquella época, tales como la expansión de la matrícula, el ingreso directo a las escuelas industriales, la ampliación del sistema educativo a nuevos sectores sociales $y$, fundamentalmente, la incorporación de los trabajadores y las trabajadoras como sujetos pedagógicos.

En cuanto a la relación entre los universitarios reformistas y los estudiantes obreros o trabajadores, Miguel Murmis relata que uno de los objetivos del movimiento estudiantil reformista "la unidad obrero-estudiantil", se encontraba lejana con respecto a sus prácticas políticas, ya que el peronismo se había instalado en modo "dictadura", por lo cual el gran propósito del movimiento estudiantil consistía en el establecimiento de "una democracia y volver socialistas a los obreros" (Toer, 1988). Dicho de otro modo, Perón había conquistado a los obreros y los universitarios debían salvarlos de su error mostrándoles que el único camino democrático era socialista.

Resulta al menos excesivo y da lugar a cierta ficción historiográfica afirmar que esta interpretación representa la percepción de todo el movimiento reformista con respecto al movimiento obrero y al peronismo. Sin embargo, en las narrativas presentadas aparece en forma reiterada una fórmula discursiva que pone de relieve el binomio dictadura versus democracia o autoritarismo fascista versus pluralismo democrático durante el
6. Estas afirmaciones aparecen publicadas en Nuevas Bases, uno de los periódicos que los socialistas editaron luego de la clausura de La Vanguardia en agosto de 1947. Aunque el periódico casi centenario siguió publicándose de manera clandestina, su irregularidad llevó al partido a publicar otros como La Lucha, El Socialista y -a partir de junio de 1950- Nuevas Bases (Martinez Mazzola, 2011, p.105-106). 
7. Nos referimos especialmente al libro de Sigal (2002), donde se destaca la poca o nula gravitación que los intelectuales tuvieron en los cargos con poder político o en la alta burocracia, a diferencia de sus pares mexicanos o brasileños, desde el momento de la fundación del Estado nacional argentino. Sigal, destaca su participación a partir del golpe de Estado de 1955 y reconstruye diferentes modalidades de participación de los intelectuales en la esfera pública. En la primera parte analiza el rol político de los universitarios animados por una iden-

tidad reformista-antiperonista, junto con su compromiso con la modernización cultural de los años sesenta. Otra obra que analiza el papel de los intelectuales es la de Suasnábar (2004), que aborda el periodo de los años sesenta y setenta tomando como recorte específico la sociología de la cultura y las dimensiones pedagógicas de la relación entre los intelectuales y el poder. Fiorucci (2011) reconoce que las imágenes derivadas de la frase "alpargatas sí libros no", aparentemente arrojada por los trabajadores el 17 de octubre de 1945, han clausurado las indagaciones sistemáticas sobre la vida intelectual del periodo y ocultan sus contradicciones. Otra historia significativa,

desde el punto de vista de su aporte

al campo intelectual, es la colección dirigida por Altamirano (2008) que integra una rica producción de estudios en distintos momentos de

la historia intelectual de la región.

8. Bourdieu afirma: "Los discursos no

son únicamente signos destinados a ser comprendidos, descifrados, son también signos de riqueza destinados

a ser valorados, apreciados, y signos de autoridad destinados a ser creídos

y obedecidos" (1985, p.28). El valor general de los discursos está en función de los poderes de aquellos grupos que tienen la capacidad de intervenir con resultados sociales efectivos en el mercado lingüístico. El valor particular de cada enunciado depende, igualmente, de la habilidad que tenga cada sujeto de convencer a sus virtuales receptores de la legitimidad, autoridad y ajuste a las fuentes de poder de su discurso específico.

Por lo tanto, la performatividad de los actos de habla solo se puede explicar por la fuerza delegada que le otorgan a los discursos los grupos sociales que construyen conflictivamente las leyes del mercado lingüístico, en cuanto que escalas de valores con las que se evalúa la eficacia simbólica real y el poder efectivamente ejercido por los hablantes en los intercambios comunicativos. primero y segundo gobierno de Perón, con énfasis en la confrontación. Murmis, activista por esa época del Centro de Estudiantes de Filosofía y Letras (CEFyL), señala que:

Realmente en ese momento se crea una corte clasista en la sociedad. Creo que salvo el hacerse peronista, había solo dos alternativas, una era la que se intentó, que podría haber llevado más a fondo, que era vincularse con los integrantes de la clase obrera que estaba en otra cosa y trabajar muy a largo plazo [...] La otra cosa era la que venía a plantear Spilimbergo, expresando [...] que había que entender a ese fenómeno social y tratar de acercarse a la clase obrera aun diciéndoles que uno no era peronista, lo que se podía hacer si se expresaba comprensión de los rasgos progresistas del fenómeno peronista. Quizás se podría haber intentado, yo no creo que se hubiera podido ir muy lejos y para muchos de nosotros no hubiera sido una actitud genuina. (Toer, 1988, p.40)

En la segunda alternativa -como afirma el entrevistado- hay un reconocimiento explícito de parte de los militantes de izquierda entrevistados por Toer en la siguiente dirección: los obreros eran peronistas y por lo tanto acercarse a ellos resultaba, al menos, contradictorio por la "identidad antiperonista que la izquierda tenía, adoptaba una postura de oposición frontal y sistemática frente al gobierno, a sus creaciones y expresiones". La opinión de los estudiantes de Ingeniería sobre la UON era que constituía un "engendro demagógico" y que respondía más bien a un ataque de Perón a los ingenieros, destinado a restar jerarquía a la profesión por motivos políticos.

Gibaja, presidente de la FUBA en 1954 y estudiante de derecho, señala:

En el primer momento, el examen de ingreso había sido bastante selectivo, hasta el 50 -y lentamente comenzó esa actitud demagógica de facilitar las cosas. Se elimina el examen de ingreso, se permite el ingreso en Ingeniería de los que vienen de la Universidad Tecnológica o del Otto Krause, se hacen cursos de promoción. Nosotros criticábamos esa situación porque pensábamos que perdía seriedad la vida universitaria. (Toer, 1988, p.26)

El campo universitario antiperonista -asociado por otros autores con el campo intelectual reformista- se fue afianzando conforme la retórica peronista iba empoderando a otros sujetos no tradicionales de las políticas liberales -confederaciones empresarias, sindicatos, gremialistas, trabajadores y trabajadoras, entre otros-, en torno a la apropiación de juicios que redimían los conceptos "cultura popular y nacional”. $7 \mathrm{La}$ puesta en marcha de los planes quinquenales y el impulso del circuito educativo técnicotecnológico que incluía a trabajadores y trabajadoras como destinatarios educativos, configuró al movimiento universitario reformista como el más autorizado -por su jerarquía intelectual- opositor al "régimen" (este último, entendido como el conjunto de signos y símbolos equivalentes a los de una "dictadura fascista" o de un "populismo autoritario"). Los reformistas, intelectuales, estudiantes, profesionales y militantes partidarios que combatían al peronismo elaboraron interpretaciones que se difundieron con autoridad y prestigio, y sellaron la matriz referente del campo intelectual a partir de 1955: discursos sobre obras demagógicas, populistas, totalitarias o dictatoriales en la historia de las universidades y del movimiento estudiantil durante ambos gobiernos peronistas. ${ }^{8}$ Estos y otros discursos recuperados en distintos documentos y testimonios a partir de la autodenominada Revolución Libertadora, proscripción mediante, ayudaron a legitimar políticas de cierre y exclusión a cualquier referente material o simbólico del peronismo.

Con posterioridad al golpe de 1955, Ernesto Laclau afirma que sobrevino una época de realineamientos en el movimiento estudiantil:

La gran divisoria que existía entonces dentro del movimiento estudiantil era entre los sectores más claramente gorilas, pro-Libertadora, nucleados en torno al Centro de 
Ingeniería. Ese era el sector más de derecha, y del otro lado estaban los sectores que eran más procambio, que estaban en una política más de izquierda. (Toer, 1988, p.65)

El siguiente testimonio de Julio Godio, describe esa situación:

\begin{abstract}
La FUA, que había podido convocar actos de medio millón de personas en el caso de la laica, no podía producir un acercamiento con el movimiento obrero. Desde el 58 en adelante hicimos el intento de acercamiento al movimiento obrero, pero fue un intento extremadamente voluntarista. Intentamos durante la laica-libre la participación de la CGT en actos de la FUA, pero nos costaba mucho. El movimiento sindical hegemonizado por el peronismo, veía al movimiento estudiantil como el viejo agente de la movilización golpista del 55, y como obviamente carecía por premisas culturales, de la cultura política apropiada para entender realmente lo que pasaba, veían en la lucha universitaria una lucha de la pequeña burguesía, de hijos de mamá, entonces el aislamiento fue absoluto. Solamente se quebraba en determinados momentos cuando había solidaridades comunes durante algunas huelgas, como por ejemplo las huelgas bancarias, la del frigorífico Lisando de la Torre y algunas otras en las cuales la FUA participó. En términos globales, el movimiento estudiantil y el movimiento obrero marcharon por caminos separados. (Godio citado por Toer, 1988, p.102-103)
\end{abstract}

Antes de finalizar este apartado sobre el conjunto de ideas que describen una racionalidad antiperonista de parte de un sector de la izquierda reformista, puede resultar ilustrativo señalar otro acontecimiento de época. Los estudiantes trabajadores agrupados inicialmente en la Federación Argentina de Estudiantes de la Universidad Obrera (FADEUO), a partir de 1956 conformaron la Federación Universitaria Tecnológica (Mollis, 1991a y 1991b, 2018). Después de numerosos intentos fallidos, entre el 7 y el 14 de octubre de 1956 en la ciudad de La Plata, estudiantes de la UON/UTN lograron participar como oyentes en la Convención de Centros de Estudiantes de Ingeniería de la FUA, y finalmente lograron su adhesión a la misma. Sus reclamos en favor de la jerarquización y la autonomía universitaria de la UTN, fueron atendidos. Frente a este hecho, el Centro de Estudiantes de Ingeniería de la UBA se desafilió de la FUA y de la FUBA. Ernesto Laclau señala que el CEI fue considerado un "baluarte de la derecha, representando la línea más reaccionaria durante esta etapa” (Laclau citado por Toer, 1988, p.59).

\title{
A modo de cierre: desde el profesionalismo liberal reformista, has- ta la creación de un circuito universitario para trabajadores
}

El pensamiento liberal decimonónico concebía la propia existencia de las universidades nacionales como una de las responsabilidades del Estado, preocupado por el destino nacional y el desarrollo de las jóvenes generaciones dirigentes. La modernización y el laicismo necesitaron a las universidades públicas nacionales tanto como las universidades necesitaron su socio fundador, el Estado, para fundamentar y garantizar su propia existencia. Del mismo modo, la expansión de las profesiones liberales (médico, ingeniero, abogado) que acompañó al desarrollo económico previo a la década del treinta, se insertó en el marco del predominio de una economía primaria exportadora y un estado modernizado y distributivo. Esto permite comprender que la estructura ocupacional entre 1900 y 1930 no se hubiera modificado sustancialmente. Las exportaciones y el sector agropecuario ocuparon un papel dominante. Hacia fines de la segunda década del siglo XX, las actividades industriales, incluyendo industrias manufactureras, minería y construcción, absorbían alrededor del $26 \%$ de la población activa, los servicios (incluyendo comercio, finanzas, servicios personales, transportes, 
9. Hemos publicado algunos trabajos que desarrollan la comparación histórica de la categoría autonomía acuñada por el reformismo argentino, y la comparamos con otras historias universitarias como la de Japón, América Latina, Estados Unidos y otros países europeos. Véase: Mollis, M. y Feldman, D. (1998).

"Accountability without Tenure: The Impact of Academic Contests on

University Teaching at the University of Buenos Aires". En Forest, J. (ed.). University Teaching. International Perspectives. University Garland

Publishing, New York and London; Mollis, M. (1998). “Autonomia e heteronomia na prática da avaliacao na Argentina". Revista RAIES, Número Temático: A Prática Da Avaliacao, CEPA, UFRFS, Porto Alegre, Brasil; Mollis, M. (1996). “El sutil encanto de la autonomía universitaria argentina. Un enfoque histórico y comparado". Pensamiento Universitario, (4-5), Buenos Aires, Argentina. comunicaciones, electricidad y otros) ocupaban el 38\% y la actividad agropecuaria el $36 \%$ restante (Mollis, 1990, p.63-97).

La distribución del ingreso, el régimen latifundista en manos de una elite agro-ganadera así como la ubicación de nuestro país en el mercado internacional, conspiraron contra el desarrollo de un sector industrial pujante que hubiera demandado la formación de recursos humanos aptos para la industrialización. Es cierto, sin embargo, que la industria derivada de los productos primarios (cerveza, alcohol, vinos algodón, etcétera) fue gestando en el interior del país la iniciativa de crear universidades que respondieran a las necesidades del incipiente desarrollo, como el caso de las de Tucumán, del Litoral y el proyecto de la Universidad de Cuyo de 1921. La evolución histórica del sistema universitario argentino, evidencia el predominio de las profesiones liberales (abogados, médicos, ingenieros civiles, escribanos farmacéuticos) entre 1901 y 1930. En las universidades más grandes (e históricamente con mayor prestigio) casi la totalidad de los graduados se concentraron en torno a Medicina, Derecho y Farmacia, y en las universidades del interior con poca población estudiantil, el conjunto de egresados se diversificó entre Derecho, Medicina, Farmacia, Ingeniería Civil y Escribanía (Mollis, 1990, p.80-87).

¿Fueron los actores estudiantiles quienes contribuyeron a fortalecer esta tendencia o fue el mercado de trabajo que condicionó el perfil profesionalizante que describimos? Unos y otros condicionaron la historia universitaria. Sin embargo, vale la pena detenerse en las demandas provenientes del movimiento estudiantil argentino para esclarecer esta relación. Obviamente, sus demandas estuvieron históricamente ligadas al tejido social donde las universidades se insertaron.

Por un lado, la demanda por la autonomía que expresaba el tipo de vinculación que deseaban mantener con el gobierno nacional (aunque en los hechos la mentada "autonomía" solo significó dependencia financiera de las arcas públicas y respeto hacia los estatutos universitarios). Por el otro, la demanda por la representación de estudiantes y graduados en el gobierno universitario, expresaba el interés por participar de los nuevos sectores que accedían a la casa de altos estudios. Finalmente, el requerimiento por la calidad y actualización de los aspectos pedagógicos y científicos de los profesores y los planes de estudio, también manifestaba una necesidad social: ya fuera el protagonismo político o profesional que les estaba reservado, ambas funciones requerían excelencia en la formación de los universitarios.

Las transformaciones del movimiento reformista se expresaron a través de la conquista de la autonomía, el cogobierno, los concursos docentes asociados con la ciudadanía universitaria, las cátedras libres y la denominada "extensión universitaria" que vinculaba a intelectuales y obreros a través de cursos y conferencias.

De este modo, las demandas intramuros convirtieron a las vitalicias y anquilosadas autoridades institucionales en cuerpos orgánicos representativos de una sociedad argentina "reparada y democrática" por el gobierno de Yrigoyen. Desde esta perspectiva, acordamos que la motivación principal de las luchas reformistas obedeció fundamentalmente a una crisis de participación en el gobierno universitario (Casanova Cardiel, 2012, Portantiero, 1978) más que al deseo de transformar estructuralmente la universidad. A pesar del importante crecimiento del número de estudiantes y graduados en el período "reformista", la institución siguió priorizando la preparación para el ejercicio de las profesiones.

La Facultad de Derecho de la UBA representa de modo ejemplificador, la función social asignada a los profesionales liberales. Así lo expresa el decano Clodomiro Zavalía en el discurso de colación de grados en 1931: 
Saldréis jóvenes doctores a engrosar las filas de una clase que aspira todavía a ser dirigente. Vuestro título os habilita como ningún otro para participar en la vida pública, y es tan fácil hoy día el acceso a ella que no tardareis en volver, trayendo de vuestras provincias o del electorado metropolitano una investidura parlamentaria. (Cucuzza, 1985, p.147 citado por Mollis, 2018, p.12)

Si repasamos la historia de estos graduados, emerge una tendencia común notable: el ejercicio de la actividad profesional poco o nada tenía que ver con las actividades productivas. Este fenómeno es fácilmente observable en el caso de los médicos y los abogados, quienes alcanzaban la independencia económica favorecida por una sociedad que valoraba la actividad individual y les reservaba importantes funciones públicas.

En cuanto a los ingenieros civiles, a diferencia del perfil profesional que se intentó fomentar para el Ingeniero de Fábrica de la UON, se orientaron fundamentalmente hacia el desempeño liberal de su profesión (asesores de empresas, proyectistas o capitalistas de la construcción).

Estos profesionales "profundamente individualistas en su contenido y en su modo de desempeño así permanecieron mientras la sociedad liberal conservó estas características. Cuanto más lejana e indirecta fuera su relación con la producción primaria o secundaria, mayor era su prestigio" (Graciarena, 1969, p.17). 


\section{Q Referencias bibliográficas}

"Altamirano, C. (2008). Historia de los intelectuales en América Latina, II. Buenos Aires, Argentina: Katz.

» Arata, N \& Mariño, M. (2013) La educación en la Argentina. Una historia en 12 lecciones, Buenos Aires: Ediciones novedades educativas

» Aristeguieta Urgoiti, J. F. (1999). UTN: mi colaboración, cuadragésimo aniversario de la promulgación de la Ley 14855. Buenos Aires, Argentina: Dunken.

»Buchbinder, P. (2005). Historia de las universidades argentinas. Buenos Aires, Argentina: Sudamericana.

»Calvillo Velasco, M. y Ramírez Palacios, L. R. (2006). Setenta años de historia del Instituto Politécnico Nacional, Tomo I, LXX, pp. 14-27. Ciudad de México, México: Instituto Politécnico Nacional.

"Cano, D. (1985). La educación superior en la Argentina. Buenos Aires, Aregentina: FLACSO - GEL.

"Casali, C. (2005). Universidad, trabajo y cultura técnica: el antecedente histórico de los debates parlamentarios de la Ley 13229 (creación de la Universidad Obrera Nacional). Cuestiones de Educación Superior. Remedios de Escalada, Argentina: UNLa.

» Casanova Cardiel, H. (2012). El gobierno de la universidad en España. La Coruña, España: Netbiblo.

»Ciria, A. y Sanguinetti, H. (1983). La Reforma Universitaria 1918-1983. Buenos Aires, Argentina: CEAL.

"Cucuzza, R. (1985). El sistema educativo argentino. Antecedentes, formación y crisis. Buenos Aires, Argentina: Cartago.

»Del Mazo, G. (comp.). (1941). La Reforma Universitaria. Compilación y Notas, 19181940. La Plata, Argentina: Centro de Estudiantes de Ingeniería.

»Dussel,I.(1990). Elmovimiento estudiantilenel surgimiento de la Universidad Tecnológica Nacional: los casos de Ingeniería de la UBA y de la UTN, 1945-1966. [Informe Final, beca de iniciación]. Facultad de Filosofía y Letras, UBA. Buenos Aires, Argentina.

»Dussel, I. y Pineau, P. (1994). De cuando la clase obrera entró al paraíso: la educación técnica estatal en el primer peronismo. En A. Puiggrós (dir.) y S. Carli (coord.), Historia de la Educación en la Argentina. Discursos pedagógicos en el imaginario social en el peronismo (1945-1955), tomo VI, pp. 107-173. Buenos Aires, Argentina: Galerna.

» Fiorucci, F. (2011). Intelectuales y Peronismo, 1945-1955. Buenos Aires, Argentina: Biblos.

"Frederic, S., Graciano, O. y Soprano, G. (2010). El Estado argentino y las profesiones liberales, académicas y armadas. Rosario, Argentina: Pro-historia.

» García Guadilla, C. (1986). El acceso a la educación superior desde la perspectiva de los estudiantes. En Tedesco y Blumenthal, La Juventud Universitaria en América Latina. Caracas, Venezuela: CRESALC/ILDES.

» Girbal-Blacha, N., Graciano, O. F., Gutiérrez, T. V. y Zarrilli, A. G. (2005). Perfiles históricos de la Argentina Peronista (1946-1955). Intelectuales, política y discurso. Buenos Aires, Argentina: Al Margen. 
»Graciano, O. (2008). Entre la torre de marfil y el compromiso político. Intelectuales de izquierda en la Argentina, 1918-1955, pp. 233-265. Bernal, Argentina: Universidad Nacional de Quilmes.

》Graciarena, J. (1971). Desarrollo, educación y ocupaciones técnicas. Revista de Ciencias de la Educación, (6), pp. 3-18. Buenos Aires, Argentina.

» Halperin Dongui, T. (1962). Historia de la Universidad de Buenos Aires. Buenos Aires, Argentina: EUDEBA.

»Kohan, N. (1999). Deodoro Roca, el Hereje, pp. 126-127. Buenos Aires, Argentina: Biblos.

»Laclau, E. (1996). Emancipación y diferencia. Buenos Aires, Argentina: Ariel Espasa Calpe.

" Mangone, C. y Warley, J. (1984) Universidad y peronismo (1946-1955). Colección "Biblioteca política Argentina", Buenos Aires, Argentina: Centro Editor de América Latina

» Martínez Mazzola, R. (2011). Nacionalismo, peronismo, comunismo. Los usos del totalitarismo en el discurso del Partido Socialista Argentino (19461953). Prismas: Revista de Historia Intelectual, 15, pp. 105-125. Bernal, Argentina: Universidad Nacional de Quilmes.

"Mollis, M. (1990). Universidades y Estado Nacional. Argentina y Japón 1885-1930. Buenos Aires, Argentina: Biblos.

»__. (1991a). La historia de la Universidad Tecnológica Nacional: una universidad para hombres y mujeres que trabajan. Realidad Económica, (99), pp. 91-111. Buenos Aires, Argentina: IADE. (1991b). La Universidad Obrera Nacional: historia de un nombre. Educacao \& Sociedade, año 12, (39), pp. 201-221. Campinas Papirus, Brasil: CEDES.

»__ (1994). La Transferencia internacional de la Universidad Humboldtiana del siglo XIX: ¿imitación o adaptación japonesa?. Estudios de Asia y Africa, 29(2), pp. 223-251. Ciudad de México, México: El Colegio de México.

》_. (2015). Reformas neoliberales y misiones universitarias latinoamericanas. En N. Mainero y C. Mazzola, Universidad en Democracia, pp. 135-161. Buenos Aires, Argentina: Miño y Dávila.

»_. (2018). Voces reformistas y formación para el trabajo: historia de una relación disputada. En A. Delich, M. Albornoz y M. Crespo (eds.), Reformar la Universidad. Lecciones de 1918, pp. 191-221. Buenos Aires, Argentina: EUDEBA - OEl.

» Neibürg, F. (1998). Los intelectuales y la invención del peronismo: estudios de antropología social y cultural. Buenos Aires, Argentina: Alianza.

» Padua, J. (1984). Educación, industrialización y progreso técnico en México. Ciudad de México, México: Colegio de México - UNESCO.

"Palacios, A. (1957). La Universidad Nueva. Buenos Aires, Argentina: M. Gleizer.

"Perez Lindo, A. (1986). Universidad, política y sociedad. Buenos Aires, Argentina: EUDEBA.

»Pineau, P. (1997). De zoológicos y carnavales: las interpretaciones sobre la Universidad Obrera Nacional. En R. Cucuzza (dir.), Estudios de la Historia de la educación durante el primer peronismo, pp. 205-229.Lujan, Argentina: Universidad Nacional de Luján. 
» Portantiero, J. C. (1978). Estudiantes y política en América Latina. Ciudad de México, México: Siglo Veintiuno.

"Pronko, M. (1997). La universidad en el Parlamento peronista: reflexiones en torno al debate de la Ley 13.031. En R. Cucuzza (dir.), Estudios de la Historia de la educación durante el primer peronismo, pp. 229-267. Luján, Argentina: Universidad nacional de Luján.

»Puiggrós, A. (dir.) \& Carli (coord.), (1994) Historia de la Educación en la Argentina.

»Discursos pedagógicos en el imaginario social en el peronismo (1945-1955), tomo VI., Buenos Aires, Argentina: Galerna.

» (1996). Que pasó en la educación argentina, desde la conquista hasta el menemismo. Buenos Aires, Argenrtina: Kapelusz.

»_. (2003). El lugar del saber. Conflictos y alternativas entre educación, conocimiento y política. Buenos Aires, Argentina: Galerna.

"Rapoport, M. (2007). Historia económica, política y social de la Argentina 18802003. Buenos Aires, Argentina: Emecé.

»Recalde, A. e I. (2010). Universidad y liberación nacional. Un estudio de la Universidad de Buenos Aires durante las tres gestiones peronistas: 1946-1952, 19521955 y 1973-1975. Recuperado de: <http://www.labaldrich.com.ar/wp-content/ uploads/2013/03/Universidad-y-Liberacio\%CC\%81n-Nacional.-Aritz-e-IciarRecalde.pdf (consulta: 20-03-2019).

»_. Recalde, A. e I. (2016 ). Intelectuales, peronismo y universidad. „, Buenos Aires, Argentina: Punto de Encuentro.

» Rothblatt, S. (2003). The Modern University and its Discontents: The Fate of Newman's Legacies in Britain and America, pp. 1-50. Cambridge, Reino Unido: Cambri Cambridge University.

"_. (2006). The European and the American universities since 1800. Cambridge, Reino Unido: Cambri Cambridge University.

"Saviani, D. (1984). Las teorías de la educación y el problema de la marginalidad en América Latina. Revista Colombiana de Educación, (13), pp 34-48.

»___ (1988). Escuela y democracia. Montevideo, Uruguay: Monte Sexto.

"Sigal, S. (2002). Intelectuales y poder en la década del 6o. Buenos Aires, Argentina: Siglo Veintiuno.

»Steger, H. A. (1974). Las universidades en el desarrollo social de la América Latina. Ciudad de México, México: Fondo de Cultura Económica.

»Suasnábar, C. (2004). Universidad e Intelectuales. Educación y Política en Argentina 1955-1976. Buenos Aires, Argentina: FLACSO - Manantial.

»Tedesco, J. C. (1985). Reproductivismo educativo y sectores populares en América Latina. En Educacao na America Latina: Os modelos teóricos e realidades Social. San Pablo, Brasil: Cortez.

"_. (1987). El desafío Educativo: Calidad y Democracia. Buenos Aires, Argentina: Grupo Editor de América Latina.

» Tenti Fanfani, E. (2005). Educación y Desigualdad. Revista Colombiana de Sociología (25), pp.23-31.

» Toer, M. (1988). El Movimiento Estudiantil de Perón a Alfonsín, 1, pp.15-19. Centro Editor de América Latina (CEAL). 


\section{Marcela Mollis}

Magister en Historia y Ciencias Sociales (Facultad Latinoamericana de Ciencias Sociales-FLACSO); profesora regular asociada con dedicación exclusiva de Historia Social de la Educación y Educación Comparada en la Universidad de Buenos Aires, directora de investigación sobre Historia de las universidades comparadas en el Instituto de Investigaciones en Ciencias de la Educación de la Facultad de Filosofía y Letras de la Universidad de Buenos Aires, Argentina. Correo electrónico: marmollis@gmail.com 
